\title{
CORRECTION
}

\section{Correction: Camptothecin suppresses NRF2-ARE activity and sensitises hepatocellular carcinoma cells to anticancer drugs}

Feng Chen ${ }^{1,2,3}$, Huihui Wang ${ }^{1}$, Jiayu Zhu ${ }^{1}$, Rui Zhao ${ }^{4}$, Peng Xue ${ }^{5}$, Qiang Zhang ${ }^{6}, \mathrm{M}$ Bud Nelson ${ }^{7}$, Weidong $\mathrm{Qu}^{5}$, Bo Feng ${ }^{2}$ and Jingbo Pi ${ }^{1}$ British Journal of Cancer (2019) 121:511-512; https://doi.org/10.1038/s41416-019-0527-1

Correction to: British Journal of Cancer (2017) 117, 1495-1506; https://doi.org/10.1038/bjc.2017.317; published online 14 September 2017

The original version of this article contained an error in Fig. $6 \mathrm{~A}$. The volumes of the tumour xenografts were incorrectly calculated. The correct figure and figure legend are below, where the volume has been calculated using $V=$ length $\times$ width $^{2} \times \pi / 6$. The interpretation of the data and conclusions are not affected.

\begin{abstract}
Open Access This article is licensed under a Creative Commons Attribution 4.0 International License, which permits use, sharing, adaptation, distribution and reproduction in any medium or format, as long as you give appropriate credit to the original author(s) and the source, provide a link to the Creative Commons license, and indicate if changes were made. The images or other third party material in this article are included in the article's Creative Commons license, unless indicated otherwise in a credit line to the material. If material is not included in the article's Creative Commons license and your intended use is not permitted by statutory regulation or exceeds the permitted use, you will need to obtain permission directly from the copyright holder. To view a copy of this license, visit http://creativecommons. org/licenses/by/4.0/.
\end{abstract}

(c) The Author(s) 2019

\footnotetext{
${ }^{1}$ Program of Environmental Toxicology, School of Public Health, China Medical University, No. 77 Puhe Road, Shenyang North New Area, Shenyang 110122 , China; ${ }^{2}$ Department of Interventional Radiology, The First Affiliated Hospital of China Medical University, No. 155 Nanjing North Road, Heping Area, Shenyang 110001, China; ${ }^{3}$ Interventional Department, Qianfoshan Hospital, Shandong University, No. 16766 Jingshi Road, Jinan 250014, China; ${ }^{4}$ School of Forensic Medicine, China Medical University, No. 77 Puhe Road, Shenyang North New Area, Shenyang 110122, China; ${ }^{5}$ Key Laboratory of Public Health Safety of Ministry of Education, School of Public Health, Fudan University, P.O. Box 249138 Yi Xue Yuan Road, Shanghai 200032, China; ${ }^{6}$ Department of Environmental Health, Rollins School of Public Health, Emory University, Atlanta, GA 30322, USA and ${ }^{7}$ MedBlue Incubator, Inc., Research Triangle Park, NC 27709, USA
}

Correspondence: Bo Feng (fb6772@sina.com) or Jingbo Pi (jbpi@cmu.edu.cn)

These authors contributed equally: Feng Chen, Huihui Wang

Published online: 26 July 2019 


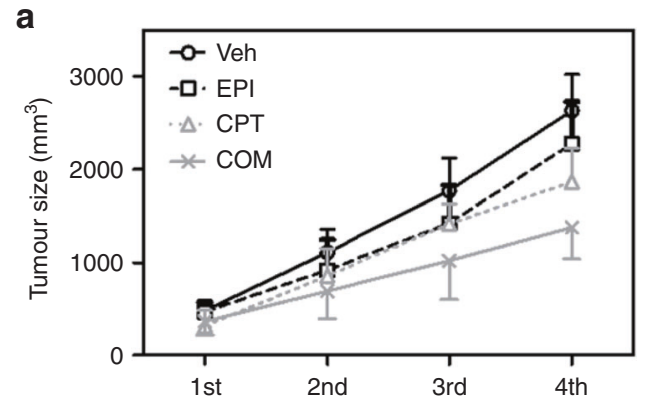

b
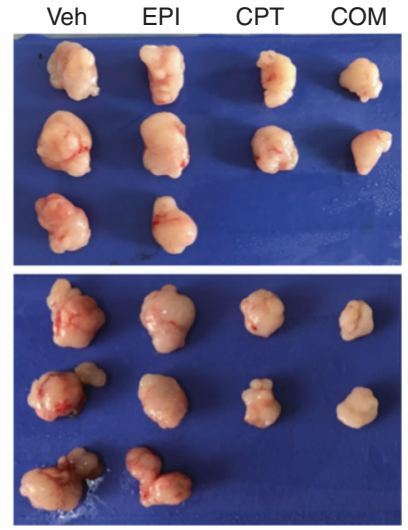

C

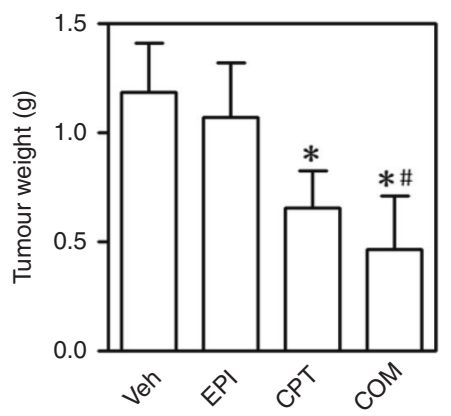

Fig. 6 CPT sensitized HCC xenografts to EPI treatment. Nude mice were injected with SMMC-7721 cells. CPT, Camptothecin; EPI, epirubicin. Mice were treated with CPT, EPI or in combination (COM) twice a week for a total of three times. At the end of the experiments, tumours were excised and weighed at the end of the experiment. a Tumour growth curves for SMMC-7721 xenografts. b Representative images of excised tumours. c Excised xenograft tumours weights at the end of the experiment. $n=8-10{ }^{*} p<0.05$ vs. Veh control. ${ }^{\#} p<$ 0.05 vs EPI 